\title{
IMAGEM, REPRODUÇÃO E REPRESENTAÇÃO DA CULTURA TIPOGRÁFICA NA WEB
}

\author{
Dennis Messa da Silva \\ Universidade Federal do Rio Grande do Sul (UFRGS) \\ dennismessa@gmail.com
}

\begin{abstract}
Resumo: Em virtude de uma série de razões técnicas, os recursos de edição da aparência tipográfica na web eram um tanto rudimentares. Entretanto, a popularização de monitores com maior resolução; o aumento da velocidade nas conexões e o acordo entre type designers e desenvolvedores de software em 2010 permitiram uma inserção de qualidades gráficas características da cultura impressa. Este fenômeno possibilita rever certas considerações a respeito da aparência da grafia na web, assim como enquadrar o objeto de estudo aos conceitos dos teóricos da cultura digital. A primeira parte deste trabalho consiste em apresentar o objeto de estudo, a segunda em aplicar um referencial teórico para confrontar com o fenômeno descrito, e por fim desenvolver uma conclusão que integre os temas em discussão.
\end{abstract}

Palavras-chave: Web Design, Tipografia Digital e WebFonts.

\begin{abstract}
By virtue of a number of technical reasons, the editing features of web typography appearance were somewhat rudimentary. However, the popularization of monitors with higher resolution, increased speed connections and the agreement between type designers and software developers in 2010 allowed an insertion of graphic qualities characteristics from print culture. This phenomenon makes it possible to revise certain considerations regarding the appearance of the spelling on the web, as well as framing the object of study to the theoretical concepts of digital culture. The first part of this paper is to present the object of study, the second to apply a theoretical framework to confront the phenomenon described, and finally develop a conclusion that integrates the topics under discussion.
\end{abstract}

Keywords: Web Design, Digital Typography and WebFonts.

\section{INTRODUÇÃO}

Desde sua origem, os recursos de edição da aparência tipográfica na web eram um tanto rudimentares, pois ofereciam limitadas opções de troca de tamanhos, pesos e estilos para a composição de textos. A gradual popularização de monitores com 
maior resolução somados ao aumento da velocidade nas conexões dos usuários e o acordo entre type designers e desenvolvedores de software em 2010 possibilitaram uma atualização e aprimoramento das ferramentas de composição tipográfica, no qual muitos destes recursos visuais são característicos da cultura impressa. $\mathrm{O}$ arquivo de fonte digital Open Type Format - OTF - possui uma série de atributos de aplicação gráfica - figura 1 - que não apenas remete aos séculos de tradição da tipografia livresca como também reflete a herança do aspecto da escrita cursiva ou caligráfica. Este modelo de arquivo, reembalado através do formato de fonte Web Open Font Format - WOFF - permite reproduzir estas qualidades visuais na web, o que antes estava disponível somente para arquivos digitais destinados à impressão.

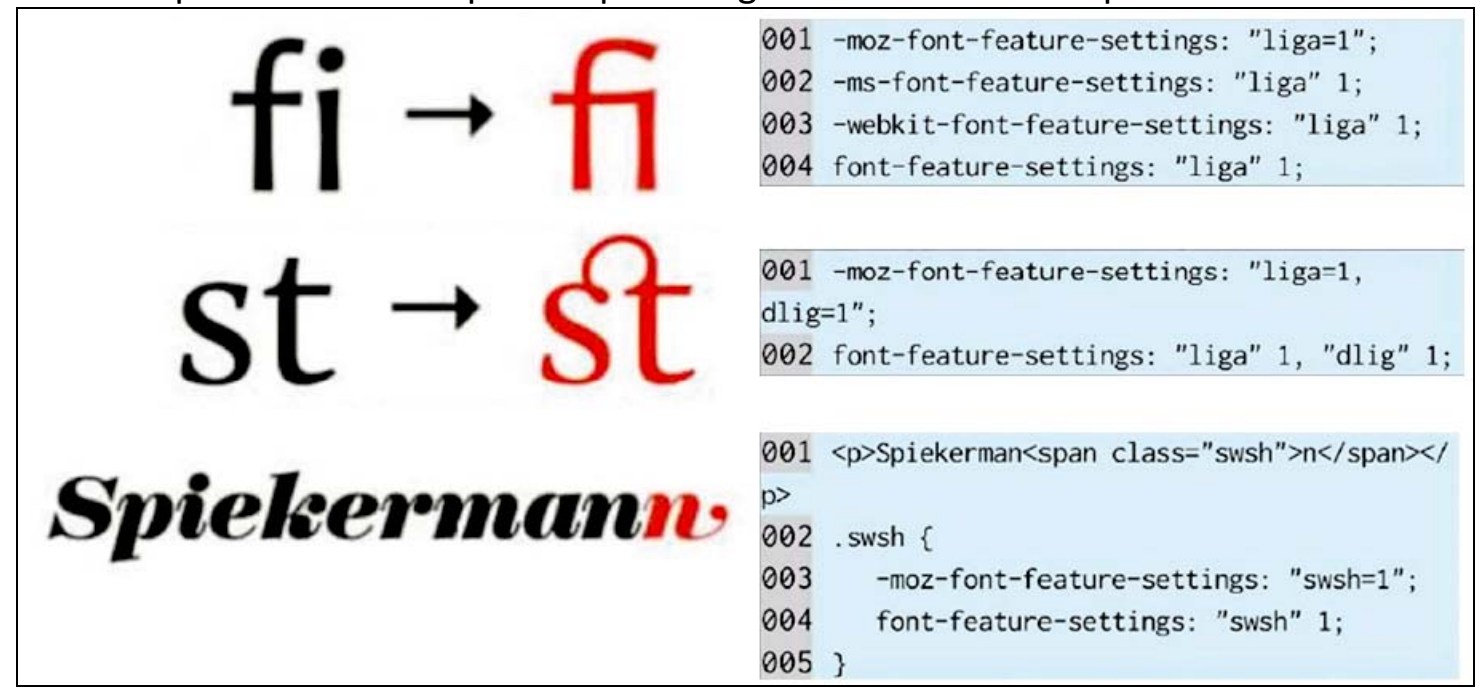

Figura 1 - recursos Open Type e suas respectivas sintaxes CSS.

Fonte: (RUTTER, 2012, p. 39-40).

Seria essas inovações uma consequência do usuário estar cada vez mais em contato com os suportes digitais? Como este fenômeno se coloca frente às teorias da escrita e da cultura digital? Os novos recursos que oferecem qualidades à imagem do texto na web possibilitam revisitar algumas considerações a respeito dos estudos do design de interfaces e enquadrar o objeto de análise aos conceitos teóricos da escrita e da cultura digital.

Sendo assim, este trabalho está organizado em duas etapas. Através de um levantamento bibliográfico, a primeira parte consiste em apresentar o fenômeno e suas características visuais mediante uma breve descrição dos códigos em Hipertext Markup Language - HTML - e marcações Castading Style Cheet - CSS. Em um segundo momento, se apresenta um referencial teórico específico da comunicação digital para confrontar com o fenômeno descrito, no intuito de desenvolver considerações na intenção de integrar os temas em discussão.

\section{A TIPOGRAFIA NA WEB}

As baixas velocidades das conexões e as incompatibilidades das licenças de uso de arquivos tipográficos levaram os primeiros web designers a produzirem páginas com somente fontes instaladas no sistema operacional dos usuários (TEAGUE, 2012). Assim, o World Wide Web Consortium - W3C, órgão que regula os padrões de construção de web sites - especificou uma pequena lista de fontes na intenção de encontrar tipos que garantiam sites responsíveis (BOS, 2010). 
Por tal razão, esses arquivos tipográficos são chamados de Safe Fonts (DAGGETT, KEW, 2009). Os tipos Arial, Helvetica, Courier, Courier New, Times Roman e Times New Roman, além de serem os arquivos tipográficos mais presentes nos sistemas operacionais Apple e Microsoft, também são versões digitalizadas de famosas fontes utilizadas no meio impresso (BOS, 2010). Teoricamente, esta ubiquidade tipográfica garante às páginas web uma aparência mais semelhante ao layout de interface projetado pelo designer, justo que cada usuário pode navegar com um computador, browser ou sistema operacional diferente (MORZININKSI, 2013).

Quanto à construção via código HTML e CSS, a composição tipográfica se restringia a mudança de cores, escalonamento livre, negritos, itálicos e apenas a aplicação um peso de fonte - regular, ou roman. Também foi determinada uma sintaxe chamada de especificação fallback ${ }^{1}$, no qual "o designer consegue determinar uma lista de fontes em ordem de preferência na esperança de que uma delas ao menos esteja disponível na máquina do usuário" (BOS, 2010) - conforme código ilustrado na figura 2. Este método de construção produziu uma limitada e pouco expressiva paisagem tipográfica, que predominou na web por quase vinte anos.

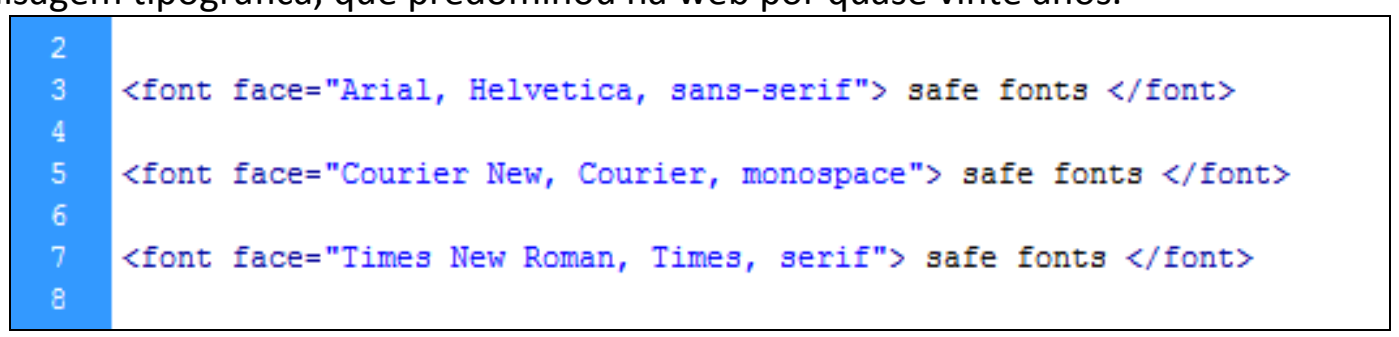

Figura 2 - código HTML/CSS, que ilustra a aplicação fallback.

Fonte: Elaborado pelo autor, com base na pesquisa realizada.

No entanto, as Safe Fonts foram perdendo sua credibilidade na medida em que crescia a quantidade de dispositivos conectados à rede - como os tablets, celulares e smartphones (PHINNEY, 2013). O fato dos recursos tipográficos na web terem pouco a oferecer em comparação ao universo da impressão (DOOLEY, 2010) e a banalização do bitmap - mediante as conexões com a internet cada vez mais velozes - contribuíram significativamente para uma mudança.

Dadas as circunstâncias tecnológicas, em 2009 o W3C passou a investir em uma especificação que permitira a inserção de diferentes e independentes arquivos de fonte na web (LIE, 2007; DOOLEY, 2010). Em 2010 um acordo entre fundidoras de tipos e desenvolvedores de browsers, foi firmado (LILLEY, 2011). Assim, o W3C determinou novas regras a partir da tag CSS @font-face - figura 3 - e um novo modelo de arquivo de fonte - o WOFF - foram criados para uso exclusivo na rede (FERREIRA, 2011).

Esse sistema de composição serve não apenas para que a fonte especificada seja interpretada no navegador do usuário independentemente de ele ter ou não o arquivo instalado em seu sistema operacional (SILVA, 2009), como também proteger as fontes de possíveis furtos, evitando assim prejuízos às fundições e designers de tipos (FERREIRA, 2011).

\footnotetext{
${ }^{1}$ Há inúmeros métodos de representação tipográfica na web, como a inserção de imagens editadas e exportadas a partir de um software de edição gráfica. Porém, estes processos não fazem uso do caractere tipográfico bruto, em forma de texto aplicado diretamente ao código HTML da página. Por esta razão, estes modos de uso não são considerados para este trabalho.
} 


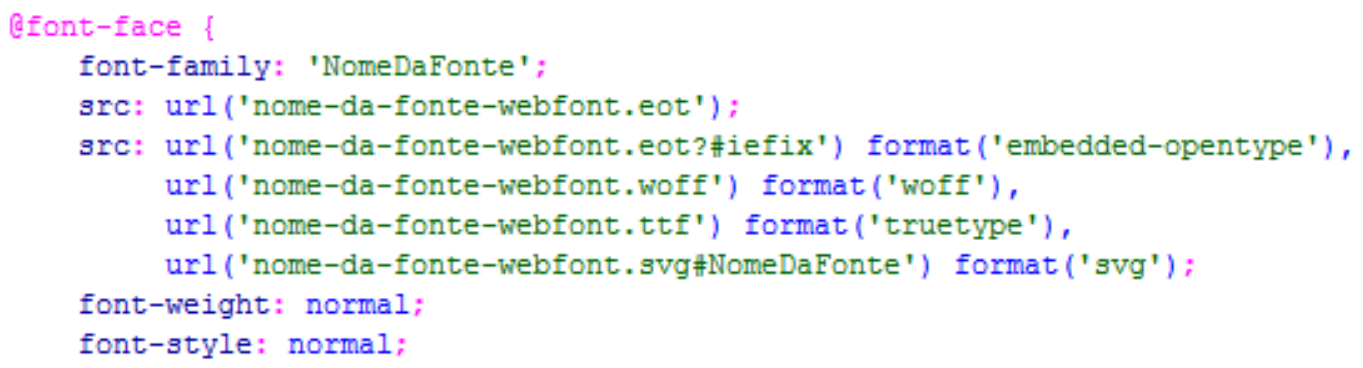

Figura 3 - marcação CSS da tag diretiva @font-face - modelo de aplicação.

Fonte: Elaborado pelo autor, com base na pesquisa realizada.

A tag@font-face caracteriza a natureza de uma WebFont. Trata-se de um recurso que faz o download automático e instalação temporária da fonte no computador sem a necessidade do usuário inserir manualmente o arquivo tipográfico em seu sistema operacional (LILLEY, 2011). Apesar de ser uma marcação CSS mais complexa para se programar, essa configuração permite que o designer aplique diferentes arquivos tipográficos em uma mesma página, possibilitando o uso de famílias de tipos. Isso garante um maior controle sobre a composição tipográfica e aposenta definitivamente as antigas especificações baseadas em Safe Fonts.

O recurso do inserir distintos arquivos não é a única inovação visual para a web, pois um único documento de fonte OpenType pode armazenar até 65 mil glifos diferentes (ADOBE, 2014). Com isso, o formato OTF pode conter diferentes desenhos, ou versões, de um mesmo caractere tipográfico para uso em diversas situações. Há glifos para cada tamanho de letra, "as fontes OT permitem a conversão automática entre variantes desenhadas especialmente para diferentes tamanhos de composição" (HOCHULI, 2013, p. 20).

A troca de glifos também ocorre mediante a adjacência entre determinados caracteres e até mesmo por uma determinação de uma última ou primeira letra em uma palavra, frase ou parágrafo na composição tipográfica (PHINNEY, 2003). A quantidade destes desenhos para substituição de glifos varia de acordo com a criatividade do designer de tipos em projetá-los.

A figura 4 ilustra alguns glifos especiais e as suas respectivas tags, no qual é possível identificar: aplicação de desenhos de caracteres alternativos, como nas letras ' $B$ ', ' $D$ ' e ' $s$ ' aplicados na primeira linha da figura; uso de versaletes, que são caracteres maiúsculos na altura das letras minúsculas, na segunda linha à direita; numerais textuais, que são caracterizados pelas hastes ascendentes e descendentes semelhantes às letras minúsculas, na terceira linha da figura; e o uso de ligaturas ornamentais e funcionais, que são basicamente glifos unidos que se formam através da combinação de caracteres adjacentes, ilustrados na última linha da figura. 


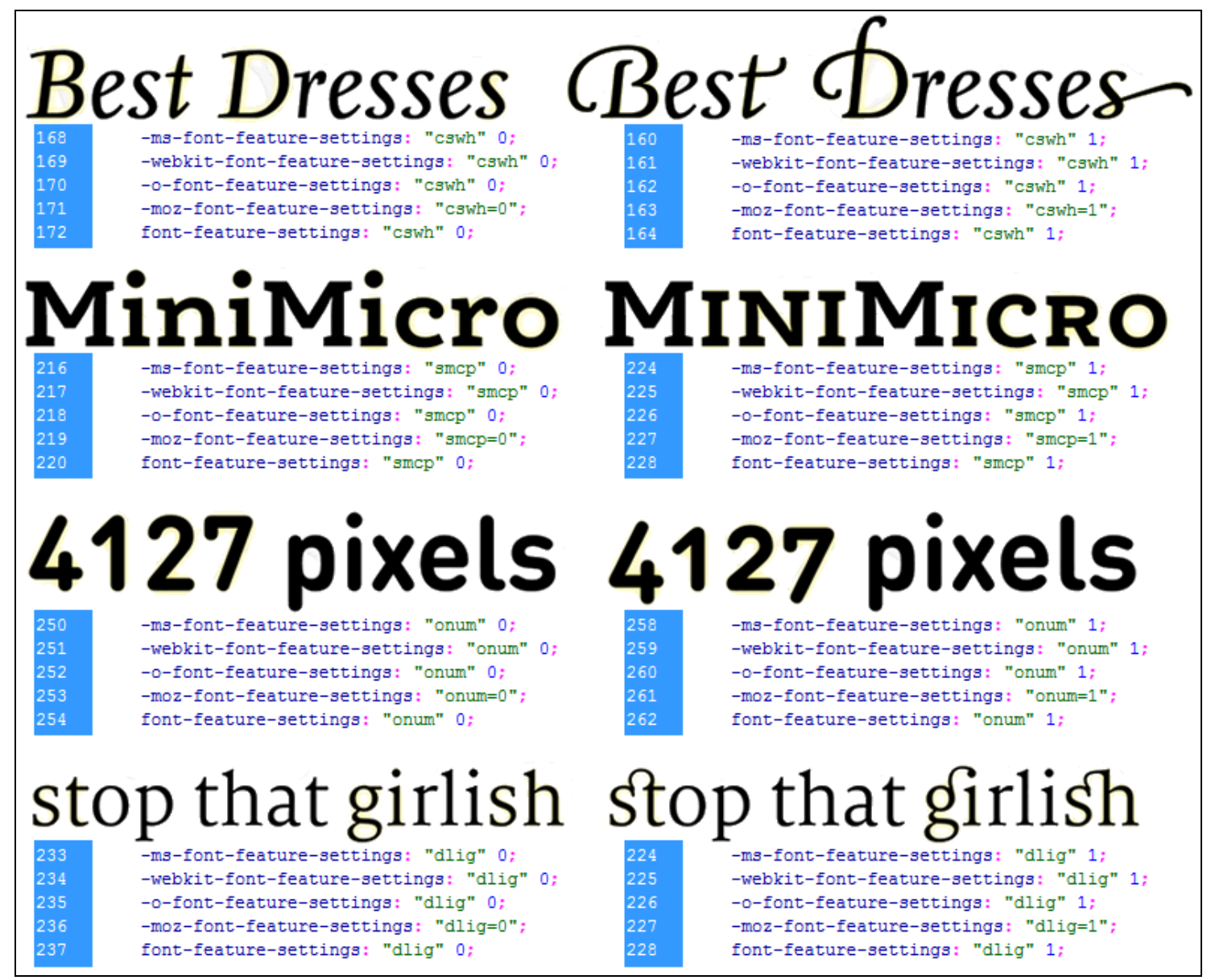

Figura 4 - de cima para baixo: exemplos de caracteres contextuais, versaletes, numerais textuais e ligaduras ornamentais com suas respectivas marcações CSS.

Fonte: http://ie.microsoft.com/testdrive/graphics/opentype/opentype-fontfont/index.html - as marcações de estilo foram criadas pelo autor.

Essas ferramentas e usos de substituição de glifos ainda não estão consolidados na web, pois nem todos os browsers fazem a interpretação dos recursos OpenType (MICROSOFT, 2012). Outro ponto a ser destacado é que as recomendações do W3C para textos dinâmicos foram concluídas somente em outubro de 2013 (DAGGETT, 2013). Este é um motivo o bastante para os desenvolvedores ainda estarem receosos com as inovações OpenType para a web. Apesar disso, os investimentos feitos pela Mozzilla, Microsoft e fundidoras digitais de tipos indicam um futuro promissor para as WebFonts (DAGGETT, 2011; RUTTER, 2012).

Em certos casos, a aplicação das propriedades OpenType não é uma tarefa simples. Para inserir um determinado caractere alternativo em um texto isolado é necessário que o designer tenha pleno conhecimento da gama de glifos contidos no arquivo OTF. O profissional deve fazer uma minuciosa análise do texto para encontrar os espaços adequados e inserir individualmente as marcações das tags <span> e <em> no documento HTML - conforme figura 5. Do contrário, o designer da página terá que generalizar os glifos em todo o bloco de texto - método que acaba por não aproveitar toda a gama de recursos OTF. Esta configuração apoiada nas tags HTML se afasta das características do texto dinâmico, ou seja, sob essas circunstâncias, dificilmente um site de notícias irá aplicar mais de três glifos diferentes para um mesmo caractere em uma determinada página. 


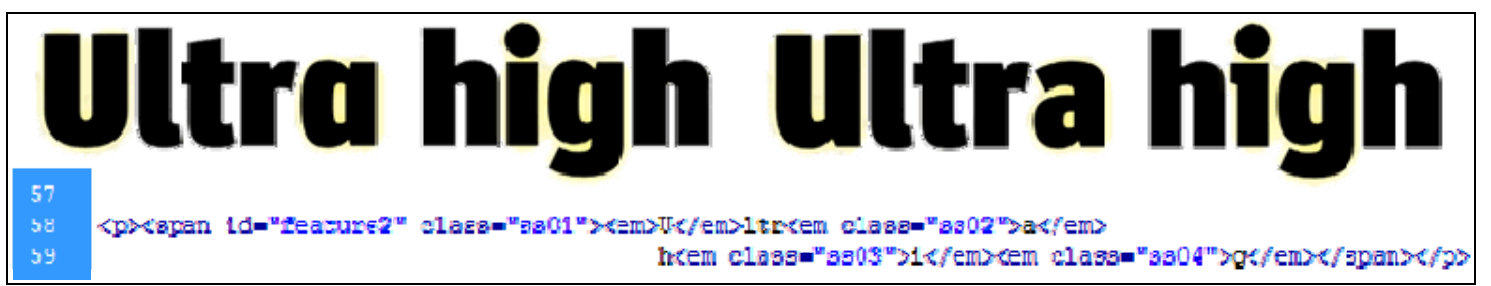

Figura 5 - glifos alternativos para os caracteres ' $U$ ', ' $a$ ', ' $i$ ' e ' $g$ ' - isolados em HTML.

Fonte: http://ie.microsoft.com/testdrive/graphics/opentype/opentype-fontfont/index.html - as imagens e código foram adaptados pelo autor.

Estas novas configurações evidenciam sensíveis mudanças visuais na web. 0 mercado do design de tipos vem disponibilizando seus serviços na intenção de atingir uma fatia de mercado que até então era inexistente (DOOLEY, 2010). Grandes empresas, como: Louis Vuitton, Red Bull e Nokia estão reforçando seu trabalho de branding através dos serviços tipográficos da WebINK². Já os grandes portais de notícias e interfaces dinâmicas da $A O L, C B S$, Wired e Wordpress optaram por expor seus sites dinâmicos com fontes da Typekit ${ }^{3}$ da empresa Adobe.

Ao analisar as interfaces web brasileiras, na intenção de identificar localmente o fenômeno das WebFonts, se sobressai o portal de notícias UOL, que atualmente é a página web do Brasil mais acessada no país - segundo os dados do Alexa ${ }^{4}$. A empresa $U O L$, por meio da agência África, contratou os serviços dos designers de tipos Crystian Cruz e Marina Chaccur para desenhar uma fonte destinada à tela e exclusiva para a UOL (CRUZ, 2014). Introduzido através de um plano de redesign do logotipo da empresa - figura 6, a família tipográfica UOL fez a sua estréia em março de 2014 e vem sendo inserida nas demais páginas do site.
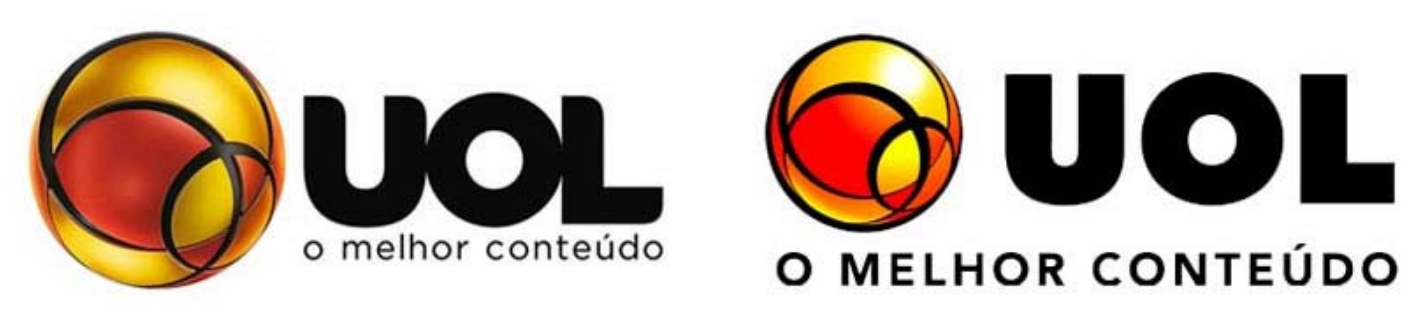

Figura 6 - o novo logotipo da UOL, e a marca anterior à direita.

Fonte: http://noticias.uol.com.br/nova-home/.

As figuras 7 e 8 ilustram a home page do portal de notícias UOL em diferentes datas, em que ambas foram extraídas de uma mesma tela de computador, com a mesma resolução e reproduzidas neste trabalho em igual proporção. A figura 7 é do dia 4 maio de 2014, em que a Safe Font Arial é predominante. Já a figura 8, do dia 30 de julho de 2014, é possível identificar o novo aspecto tipográfico da página.

Ao comparar as fontes, são nítidas as diferenças entre as manchetes das páginas e a estratégia da agência Africa em preparar um desenho de letra coerente com o desenho do novo logotipo da UOL. Este cenário confirma que algumas empresas estão interessadas em reforçar a sua marca através de um trabalho de branding, onde o aspecto da tipografia institucional é fundamental.

\footnotetext{
${ }^{2}$ Disponível em: <http://www.webink.com/>. Acesso em 15 jan. 2014.

${ }^{3}$ Disponível em: <https://typekit.com/>. Acesso em 15 jan. 2014.

${ }^{4}$ Banco de dados mantido pelo grupo Amazon, em que informa os endereços na web mais acessados do mundo. Disponível em: <http://www.alexa.com/>. Acesso em 07 set 2014.
} 


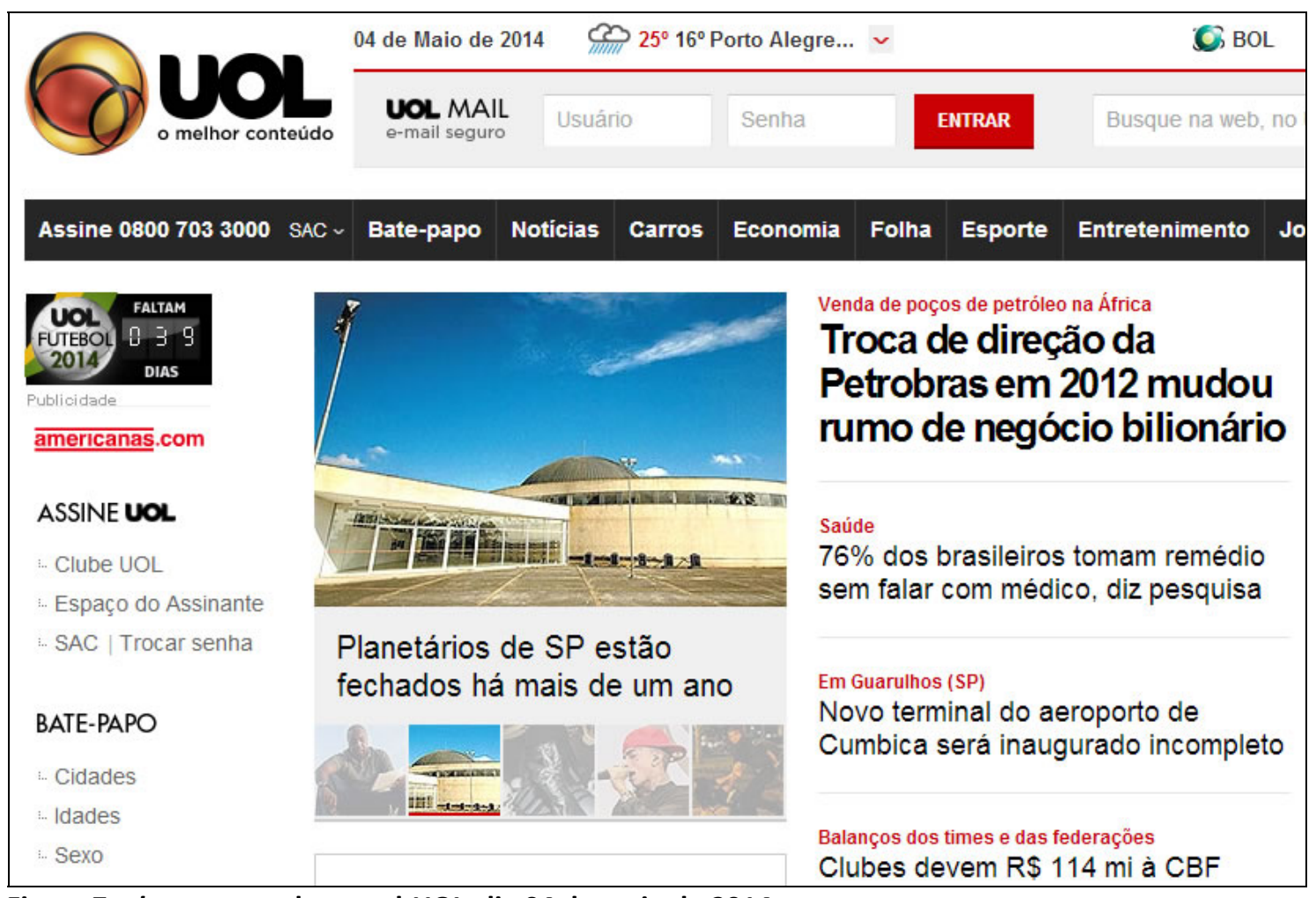

Figura 7 - home page do portal UOL, dia 04 de maio de 2014.

Fonte: http://www.uol.com.br/.

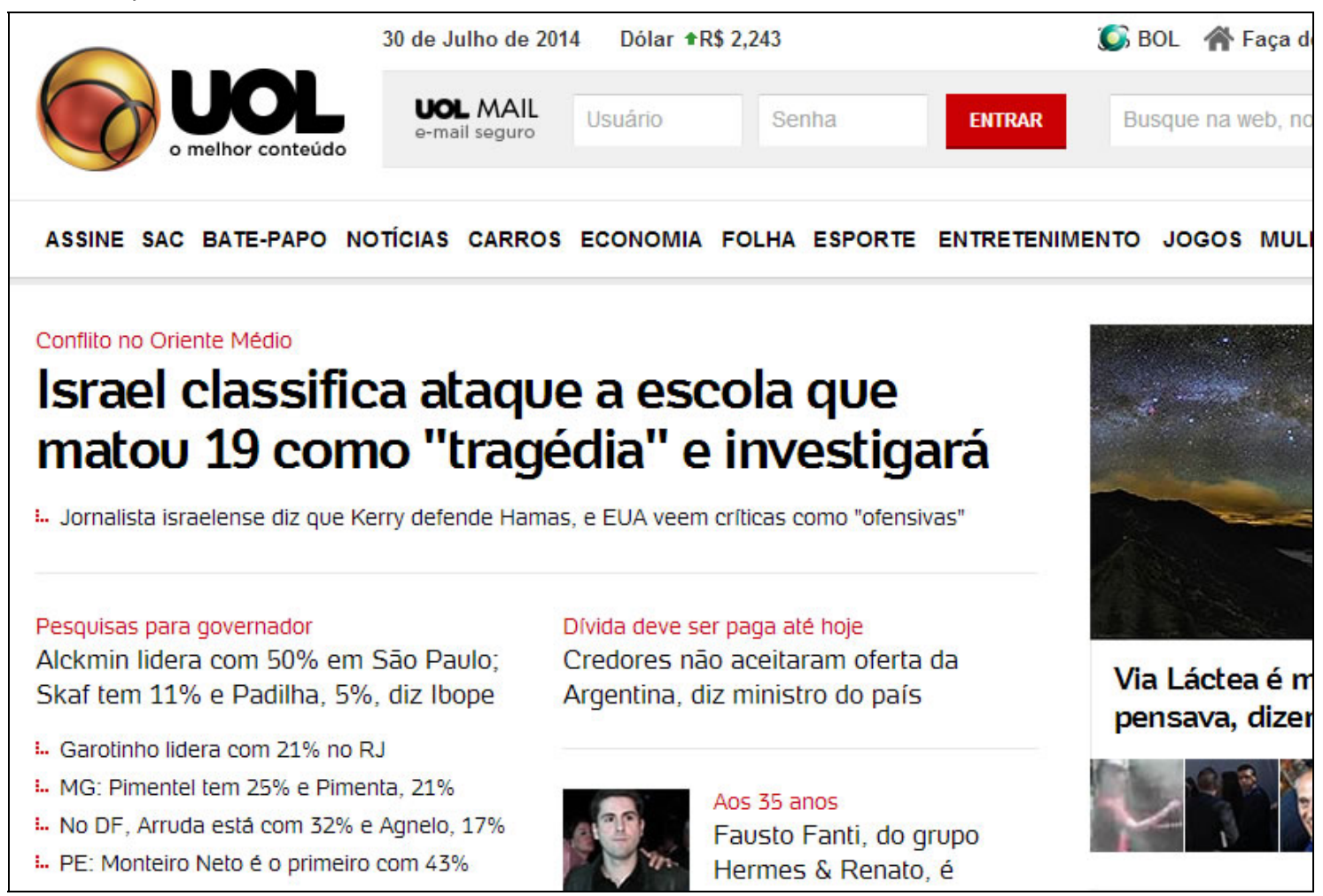

Figura 8 - home page do portal UOL, dia 30 de julho de 2014.

Fonte: http://www.uol.com.br/.

Como os portais de notícias trabalham com uma alta densidade de texto na tela, essas mudanças são mais evidentes. Suas necessidades indicam o uso de uma extensa família tipográfica para garantir uma adequada organização da informação. Uma tipografia específica para um determinado suporte também pode assegurar desempenhos de legibilidade e leiturabilidade. 


\section{A REPRESENTAÇÃO TIPOGRÁFICA NA WEB}

Dado o contexto, através das Safe Fonts, a web se configurou em um ambiente visualmente amorfo, no que diz respeito às retóricas tipográficas. Antes das WebFonts, uma fonte não segura se apresentava de forma muito pontual, limitada a pequenos blocos em bitmap ou $S W F^{5}$. É importante frisar que as Safe Fonts são, essencialmente, adaptações de tipos consagrados da cultura impressa. A Times New Roman é uma versão digital dos tipos produzidos em 1929, para o jornal Londrino The Times (ROCHA, 2012). A fonte Arial é acusada de ser uma mera cópia da fonte sem serifa Suíça Helvética, um desenho de letra para as propagandas dos anos 1960 (GARFIELD, 2012). Já a Courier se trata de uma adaptação digital das fontes produzidas para máquinas de escrever (TYPEART, 2013). Isso conduz a considerar mais uma evidência de que o computador "é o filho da cultura impressa" (MURRRAY, 2003, p. 23).

O cenário da baixa resolução dos monitores também prejudicou o uso da imagem tipográfica serifada - obrigando o uso quase que exclusivo de tipos de estética funcionalista, como as fontes Arial, Tahoma e a Verdana (NIELSEN, 2012). Estas afirmações favorecem a hipótese de que a forma da letra pouco se reinventou mediante a natureza bruta do pixel - como sustenta Bolter (2001) em sua obra Writing Space.

O serrilhado da letra bitmap criou um estilo gráfico, como pode ser visualizado através dos trabalhos de Susan Kare ${ }^{6}$ e Zuzana Licko ${ }^{7}$, mas parece não ter sido capaz de desenvolver convenções que assegurassem um aspecto plenamente funcional para a leitura tela. David Bolter $(2001,2003)$ afirma que os tipógrafos entregaram a responsabilidade de oferecer a qualidade tipográfica digital aos engenheiros de software e desenvolvedores de hardware, apesar de afirmar que:

O ciberespaço não é como alguns entusiastas têm argumentado, divorciada do mundo natural e social que conhecemos, mas sim, é uma expressão e extensão de ambos (BOLTER, 2001, p. 98).

Neste sentido, Ladislas Mandel (2011) transfere a culpa da pobreza visual à ordem do capital, que sempre exigiu pressa nas trocas de informação visual. Contudo, o autor esquece de que o próprio aspecto visual apressado da letra escrita também foi um elemento gráfico reaplicado que serviu de afirmação aos cânones da cultura impressa. Por exemplo: as hastes ascendentes e descendentes das letras minúsculas ' $b$ ', ' $d$ ', ' 'g' e 'l' são um exemplo de herança da escrita cursiva desencadeada no império romano (HEITLINGER, 2010). Esta forma irregular garante a facilidade em decodificar caracteres produzidos de maneira manual. A palavra cursiva vem do latim: "currere = correr, apressar-se" (HOCHULI, 2013, p. 22). As formas das letras minúsculas auxiliam na interpretação de palavras em textos corridos, ou seja, contribuem para leiturabilidade (HOCHULI, 2013).

Entretanto, não é totalmente um equívoco afirmar que a pressa em comunicar prejudica a qualidade da imagem da escrita. Na cultura impressa, os atributos

\footnotetext{
${ }^{5}$ Abreviação de Shockwave Flash. Formato de arquivo criado a partir do software para animação Adobe Flash - muito utilizado para produzir arquivos multimídia para a web.

6 Designer de interfaces especialista na criação de ícones e fontes bitmap, disponível em: http://www.kare.com/.

${ }^{7}$ Designer de tipos pioneira no desenvolvimento independente de fontes digitais, mais detalhes em: http://www.emigre.com/.
} 
tipográficos definharam-se à medida que os processos de impressão ganharam a velocidade da revolução industrial. Este fato desequilibrou a queda de braço com os valores históricos da tipografia (HEITLINGER, 2010). Neste sentido, a cultura tipográfica não conseguiu acompanhar os rápidos processos evolutivos da tecnologia da impressão. Abriu-se um hiato na história da cultura dos tipos. Em contrapartida, o estilo de fonte bitmap parece estar perdendo espaço e sendo substituído pelo aspecto tradicional da escrita.

Tanto que o formato de arquivo OpenType oferece a chance das antigas qualidades serem retomadas, mas com novos propósitos - fenômeno que pode ser enquadrado à teoria de Remediação das mídias (BOLTER, 2001). As formas da imagem tipográfica por si só carregam valores históricos, mas que na web sua função atende pela identificação e construção de sentido a uma marca, produto ou serviço:

Longe de serem inocentes, as coisas trazem consigo uma robusta tradição filosófica. Não podemos nos esquecer de que, em sociedades capitalistas, as coisas deixaram de ser coisas. São mercadorias e, como tal, impregnadas de fetichismo, valores psíquicos dissimulados que o capital adere às coisas (SANTAELLA, 2005, p. 98).

Por este fato - independente das qualidades das formas das letras - é comum encontrar uma enorme quantidade de revivals tipográficos servindo a web. Sites brasileiros, como A Folha de São Paulo, O Estado de São Paulo e $O$ Globo aderiram às WebFonts, no qual readequaram arquivos tipográficos institucionais próprios que antes eram publicados somente para o jornal impresso. Porém, os novos recursos indicam uma tentativa em atender parte dos antigos anseios dos críticos da arte digital, como pode ser visto em uma crítica logo abaixo, que é anterior a 2010:

$O$ design de interação parece ter perdido a sua batalha contra a interface da estupidez. A metáfora do escritório da década anterior foi trocada por uma adaptação das perspectivas de primeira página de jornal como a dominante arquitetura da informação. [...] Listas telefônicas, dicionários, dinheiro de papel tiveram tipografia e design gráfico decente. Então por que não também nos web sites mais visitados do mundo? (LOVINK, 2003, p. 334).

As WebFonts vislumbram não apenas uma revisitação à criticada cultura da mídia de massa impressa, mas também à toda história da impressão. Fomentam uma necessidade pela identidade e atração visual. As WebFonts são configurações digitais que estão muito mais próximas de pagar "homenagens ao códex impresso e outros materiais baseados no papel, enquanto que ao mesmo tempo estão para substituí-los" (BOLTER, 2001, p. 79). Desta forma, poder-se-ia dizer que a presença da herança da cultura impressa e da escrita é mais recorrente em projetos tipográficos digitais inovadores que aqueles desenvolvidos sem tais intenções. As virtudes OpenType carregam basicamente uma tradição visual, independente do desenho da letra. 0 simples desejo de substituir dois glifos por outro que os represente é por si só um ato de revitalização da tipografia e conduzem para o seguinte ponto de vista:

A aparência da palavra digital tem o maior efeito cultural de permitirnos, pela primeira vez em séculos, de facilmente perceber o grau em que nos tornamos tão acostumados para as qualidades e efeitos culturais do livro que nós inconscientemente transferimos para as produções culturas orais e manuscritas (LANDOW, 2006, p. 102). 
Os recursos oferecidos pelo OpenType ainda são muito recentes, comparados a trajetória histórica dos suportes digitais. Embora esta tecnologia tenha sido concebida em 1997 (ADOBE, 2014), somente em 2003 que suas ferramentas foram disponibilizadas para os designers gráficos (PHINNEY, 2003). De lá para cá, a paisagem tipográfica, vem se alterando lentamente, no qual os designers gráficos vêm reciclando os mais de cento e cinquenta anos de indigência tipográfica estabelecida por linotipos, monotipos e máquinas de escrever (SILVA, 2011).

\section{CONSIDERAÇÕES FINAIS}

Apesar de suas recentes conquistas, as qualidades tipográficas propostas pelas WebFonts ainda têm um longo caminho até se estabelecer. Ao analisar as páginas produzidas com WebFonts, conclui-se que as transformações na web ainda são sutis, principalmente ao comparar o estado visual das páginas atuais com a gama dos recursos OTF. Talvez, por isto, ainda seja muito prematuro traçar conclusões a respeito do futuro da forma da letra na web, mas já é possível afirmar que se vive uma fase de efervescência tipográfica. Esta situação parece apontar um futuro promissor aos type designers.

Os novos recursos possibilitam a reprodução de quase todo o potencial do aspecto tipográfico antigo. Talvez essa nova tecnologia tipográfica disponível não seja apenas uma saída comercial para type designers e web designers, mas uma chance de recuperar e reconfigurar valores que qualifiquem estas atividades profissionais.

\section{REFERÊNCIAS}

ADOBE. Adobe Type / OpenType. Disponível na internet por http em: <http://www.adobe.com/products/type/opentype.html> Acesso em 11 fev. 2014.

BOLTER, Jay David. Writing Space: Computers, Hypertext, and the Remediation of Print. 2a ed. New Jersey: Lawrence Erlbaum, 2001.

BOLTER, Jay David; GRUSIN, Richard. Remediation: Understanding New Media. Massachusetts: MIT Press, 2001.

BOS, Bert. The history of a model for fonts on the Web. Disponivel na internet por http em: <http://www.w3.org/Talks/2010/0313-Fonts-SXSW>. Acesso em 04 out. 2013.

CRUZ, Crystian. Type Family UOL. Disponível na internet por http em: $<$ https://www.behance.net/gallery/Type-Family-UOL/15639563>. Acesso em 31 jul 2014.

DAGGETT, John. Ampersand Conference. The Future of CSS Typography. Disponível na internet por http em: <http://ampersand.s3.amazonaws.com/2011/>. Acesso em 11 fev. 2014.

DAGGETT, Johb. CSS Fonts Module Level 3. Disponível na internet por http em: <http://www.w3.org/TR/2013/CR-css-fonts-3-20131003>. Acesso em: 12 fev. 2014.

DAGGETT, John; KEW, Jonathan. Graphic bits - ATypI 2009. Disponível na internet por http em: <http://blog.mozilla.org/nattokirai/2009/11/04/atypi-2009>. Acesso em 21 out. 2013. 
DOOLEY, Michael. The Future of Web Fonts Is Sooner Than It Used To Be. Disponível na internet por http em: <http://www.printmag.com/design-inspiration/the-future-ofweb-fonts-is-sooner-than-it-used-to-be>. Acesso em 12 out. 2013.

FERREIRA, Gustavo. OpenType features in web browsers. Disponível na internet por http em: <https://www.typotheque.com/articles/>. Acesso em 11 fev. 2013.

GARFIELD, Simon. Esse é o meu tipo. Rio de Janeiro: Zahar, 2012.

HEITLINGER, Paulo. Alfabetos: caligrafia e tipografia. Lisboa: Dinalivro, 2010.

HOCHULI, Jost. $O$ detalhe na tipografia: uma explicação resumida e precisa sobre as questões que se ocupam da legibilidade dos textos. São Paulo: Martins Fontes, 2013.

LANDOW, George. Hypertext 3.0: Critical Theory and New Media in an era of Globalization. 3a ed. Baltimore, Maryland: The John Hopkins University Press, 2006.

LIE, Håkon Wium. W. CSS @ Ten: The Next Big Thing. Disponível na internet por http em: <http://www.alistapart.com/articles/cssatten>. Acesso em 26 jun. 2012.

LILLEY, Chris. W3C: Fonts on the Web. Disponível na internet por http em: <http://www.w3.org/Fonts $>$. Acesso em 11 out. 2013.

LUPTON, Ellen. Pensar com Tipos. São Paulo: Cosac Naify, 2006. 184 p.

LOVINK, Geert. Dark Fiber: Tracking Critical Internet Culture. Massachusetts: MIT, 2003.

MANDEL, Ladislas. O Poder da Escrita. São Paulo: Rosari, 2011.

MURRAY, Janet Horowitz. Hamlet no Holodeck: O Futuro da Narrativa no Ciberespaço. São Paulo: UNESP, 2003.

MICROSOFT. Typography. Core fonts for the web. Disponível na internet por http em: <http://www.microsoft.com/typography/fonts/web.aspx>. Acesso em: 18 fev. 2013.

MORZINSKY, Jacob. Safe web fonts. Disponível na internet por http em: <http://web.mit.edu/imorzins/www/fonts.html>. Acesso em 8 nov. 2013.

NIELSEN, Jakob. Serif vs. Sans-Serif Fonts for HD Screens. Disponível na internet por http em: <http://www.useit.com/alertbox/web-typography.html>. Acesso em 01 mar. 2014.

PHINNEY, Thomas. TipoGráfica: Revista de Diseño. La Experiencia OpenType. Buenos Aires: FontanaDiseño, 2004. TPG 62, 27-33.

PHINNEY, Thomas. Web Safe Fonts Are Dead. Disponível na internet por http em: $<$ http://www.howdesign.com/resources-education/web-safe-fonts-are-dead-fontguru-thomas-phinney-talks-web-fonts>. Acesso em 8 out. 2013.

ROCHA, Cláudio. Novo Projeto Tipográfico. São Paulo: Rosari, 2012.

RUTTER, Richard. Web Designer. The Future of Fonts is Now. Bournemouth: Imagine Publishing, 2012. Issue 198, 38-43.

SANTAELLA, Lucia. Midias Locativas: a internet de lugares e coisas. Revista FAMECOS, 35, 2008, pp. 95-101. 
SILVA, Maurício Maujor Samy. A diretiva @font-face das CSS3. Disponível na internet por http em: <http://www.maujor.com/tutorial/css3-@font-face.php>. Acesso em 12 jun. 2012.

SILVA, Sérgio Luciano. Faces e Fontes Multiescrita: Fundamentos e Critérios de Design Tipográfico. 2011. 155 f. Dissertação (mestrado) - Universidade Estadual de Minas Gerais, Programa de Pós-Graduação em Design.

TEAGUE, Jason. HOW: Web Type Revolution. Disponível na internet por http em: $<$ http://www.howdesign.com/design-creativity/fonts-typography/web-typographyrevolution>. Acesso em: 09 out. 2013.

TYPEART FOUNDRY. TypeArt History of Courier. Disponível na internet por http em: <http://www.typeart.com/history.asp?FID=43>. Acesso em 27 fev. 2013. 